Proceedings of the Pakistan Academy of Sciences:

A: Physical and Computational Sciences 58(3): 31-42 (2021)

Copyright (C) Pakistan Academy of Sciences

ISSN (Print): 2518-4245; ISSN (Online): 2518-4253

https://doi.org/10.53560/PPASA(58-3)627

\title{
Geo-Statistical Estimation and Temporal Distribution of Wind Speed Data of Karachi Airport
}

\author{
Muhammad Irfan ${ }^{1 *}$, Salman Zubair ${ }^{2}$ and Abid Hussain ${ }^{3}$ \\ ${ }^{1}$ Institute of Space Science and Technology, University of Karachi, Karachi, Pakistan. \\ ${ }^{2}$ Department of Geography, University of Karachi, Karachi, Pakistan. \\ ${ }^{3}$ Department of Applied Physics, University of Karachi, Karachi, Pakistan.
}

\begin{abstract}
Karachi city is a coastal city near the Arabian sea. Due to its location, wind speed may provide a sustainable small scale wind energy system as well as reduction in power shortage in the city. In this study, wind speed data of Karachi Airport station at $10 \mathrm{~m}$ height is used to estimate wind speed in the surrounding area with reference to measured wind speed data of the station. This estimated wind speed will then be helpful to assess small scale wind power generation at the unsampled locations. Geo-Statics tool in ArcGIS version 10.1 software was utilised to estimate measured wind speed using different interpolation methods. Descriptive statistics were used to analyse and compare measured and estimated wind speed. The analysis summarises the effectiveness of the estimated wind speed. Time series variations of the wind speed data was also analysed. Temporal mapping showing seasonal variations of the wind speed. The descriptive statistics illustrated a high value of correlation coefficient ' $r$ ', coefficient of determination $\mathrm{R}^{2}$ which is $99.8 \%$ for Ordinary and Universal kriging interpolation methods, while it was calculated $99.6 \%$ for Simple kriging. A slightly higher coefficient of variation resulted in Ordinary and Universal kriging methods than the Simple kriging method. The results indicated that all three kriging methods performed better and are more effective to estimate wind speed and wind power in the surrounding area and for Temporal display.
\end{abstract}

Keywords: Wind Speed Estimation, Geographical Information System (GIS), Geostatistical Analysis, Kriging Interpolation, Descriptive Statistics, Wind Power Potential

\section{INTRODUCTION}

The use of fossil fuels for power generation is hazardous for human life and the environment. It is a costly fuel and put a burden on country's economy. Pakistan has been a developing country using fossil fuels for power generation for many decades. Renewable energy provides a cost-effective and environment friendly solution to this problem. This would make our economy better and make our environment clean and green. One of the important sources of renewable power generation is wind. It is abundantly available in Pakistan, particularly at the country's coastal belt. Due to its location at the coastal line towards the Arabian sea, Karachi city is blessed with immense wind power potential. Different studies were presented on wind power resource assessment at the coastal areas of Karachi and Baluchistan, including Hawksbay, Paradise point, Pasni and interior areas of Sindh province. Today, wind resource assessment is an important and commonly studied topic in the scientific world. The wind conditions at specific locations have been analysed in several studies. Wind potential was assessed by estimating the Weibull parameters in Osmaniye, Turkey, using a graphical method considering hourly time-series measured at the local meteorological station belonging to the Turkish State Meteorological Service [1]. The author [2] measured wind speed frequency above various thresholds needed to push pets among hosts. For this assessment, three statistical distributions (Weibull, Lognormal and Logistic) were used to model the wind behaviour by considering the data registered in a meteorological station in Inner Mongolia. Very few studies have been reported in

Received: July 2021; Accepted: September 2021

*Corresponding Author: Muhammad Irfan <irfanf01@hotmail.com> 
past which compared the effectiveness of different spatial interpolation methods in estimating winds speed. Many researchers [3-7] previously compared different interpolation methods for temperature and precipitation. One presented wind speed and power density in Northern Mexico [8]. The author analysed the spatial and temporal information about wind energy resources. The kriging method was utilised to interpolate the data collected at 221 meteorological stations. Wind speed was estimated and validated using spatial interpolation [9]. Seven interpolation methods were analysed to estimate daily mean wind speed across England and Wales and found differences in their performances [10]. Geostatistical analysis was utilised on air pollution using different time scale in Aburra Valley, Columbia and found that this method accurately captured the variability of the air pollutants and satisfactory results were obtained [11]. The author utilised Weibull function to estimate wind power potential at coastal areas of Pakistan, including Karachi, Ormara, Jivani and Pasni, for small scale wind power generation for irrigation purposes. The results showed that Pasni and Jivani have higher annual wind speeds than other areas [12]. The author [13] reported that Pakistan Metrological Department PMD, conducted a survey during 2003-2005 for wind power potential analysis at different coastal areas of Sindh province including Gharo, Ketibandar, Metthi, Thata, Jamshoro etc. and found good wind speed to install wind farms in these areas. As previously mentioned, southern and some northern mountains of Pakistan have excellent resources for wind energy [14]. Weibull distribution was utilised to analyse wind speed at Paradize point, a coastal area of Karachi [15]. It was mentioned that Pakistan coastal belt is about $1100 \mathrm{~km}$ long whereas $250 \mathrm{~km}$ lies in Sindh province. The author analysed one year wind data of Jamshoro coast in Sindh and mentioned that the maximum wind speed at this station at $50 \mathrm{~m}$ height reaches $13.9 \mathrm{~m} / \mathrm{s}$. The author utilised mathematical functions and stated that this station could produce 2.1 GWh units of wind energy annually [16]. As mentioned by [17] in a technical and economic assessment of wind power at Noori-Abad, a coastal area in Sindh and applied Weibull function for wind speed analysis at 50 meter height and found that the cost of wind energy is about US\$0.02189/ $\mathrm{kWh}$. Previously mentioned in a review that Sindh province contributes $935 \mathrm{MW}$ of wind power to the national grid of Pakistan [18]. Geostatistical and Non-geostatistical techniques were compared in estimating wind speed and wind potential at unsampled areas in Sindh, Pakistan [19].

This study is different from previous studies as we focused on analysing wind speed of Karachi city's urban area for small scale wind power generation. In the past, few studies were reported which utilised Geostatistical and statistical analysis tools to analyse the behavior of wind speed in Karachi city. In this study, Geostatistical and statistical analysis is employed to summarise wind speed distribution around Karachi Airport station. This will also support installing a wind turbine on a community basis.

\section{MATERIALS AND METHODS}

\subsection{Study Area and Data Description}

Karachi is the capital city of Sindh province, located in south-eastern part of Pakistan at the coast of the Arabian Sea. It is a subtropical region. Its geographical location is $24.8607^{\circ} \mathrm{N}$ and $67.0011^{\circ}$ E. The study area lies in the eastern part of Karachi city and its location is $24.9008^{\circ} \mathrm{N}$ and $67.1681^{\circ} \mathrm{E}$. The summer high temperature ranges around $37^{\circ}$ $\mathrm{C}$ to $44^{\circ} \mathrm{C}$ during the period from May to October and winter low temperature lies around $6^{\circ} \mathrm{C}$ to $12^{\circ}$ $\mathrm{C}$ from December to February. Location of Karachi Airport and vicinity area is shown in (Figure 1). The total area of Karachi Airport is $11.5 \mathrm{~km}^{2}$. Figure shows that the surrounding area is comprised of small houses.

\subsection{Data Description}

To estimate wind speed, One-year monthly average wind speed data in meter/second $(\mathrm{m} / \mathrm{s})$ at $10 \mathrm{~m}$ height of Karachi Airport station for the year 2010 was utilised. The data was acquired from PMD (Pakistan Metrological Department). The structure of methodology is explained in the flow diagram presented in (Figure 2).

\subsection{Kriging Interpolation}

It was stated earlier that Kriging is a Geostatistical stochastic technique that uses a linear combination of weights at the known geographical location to 


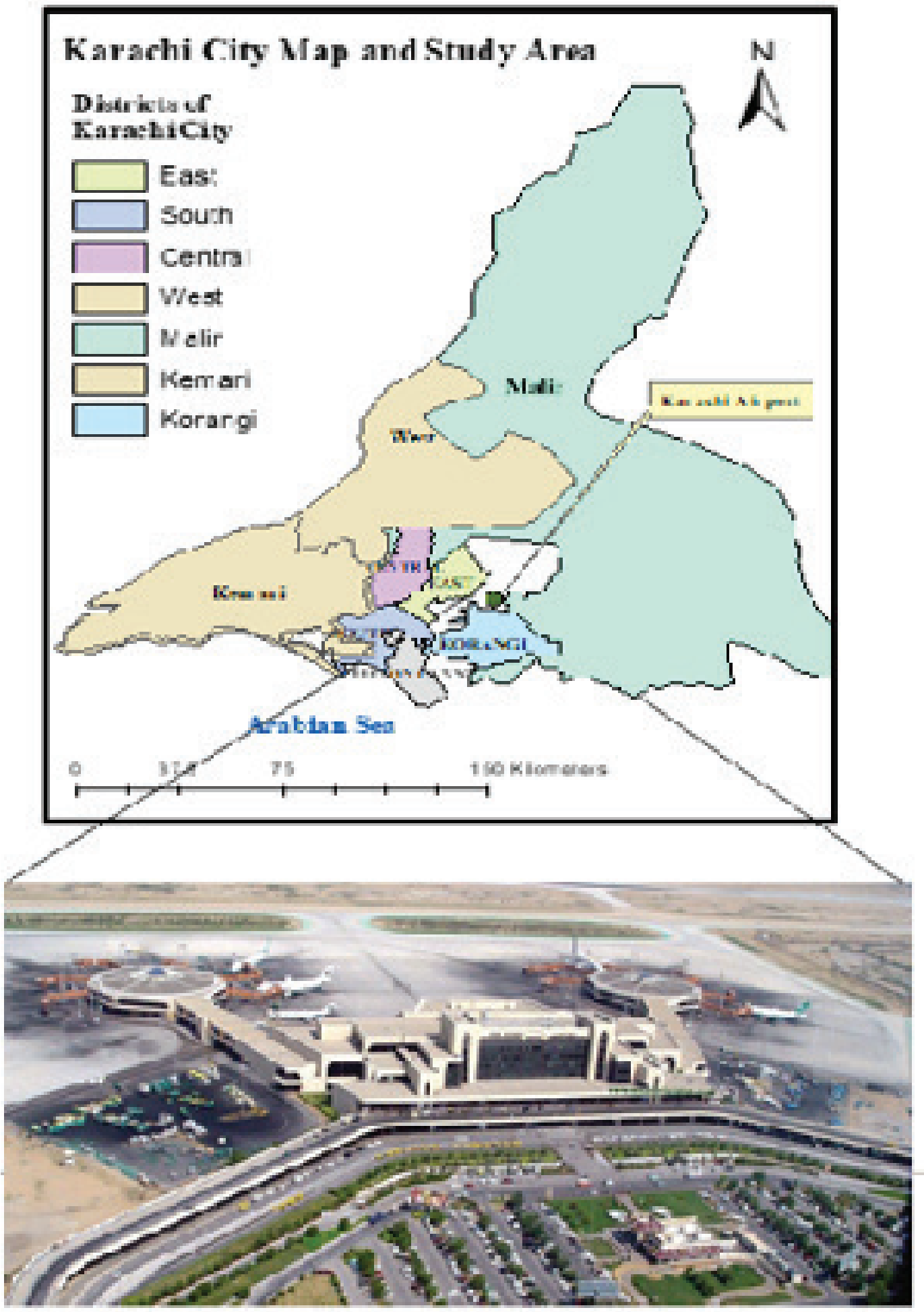

Fig. 1. Karachi city map and aerial view of Karachi Airport and surrounding area 


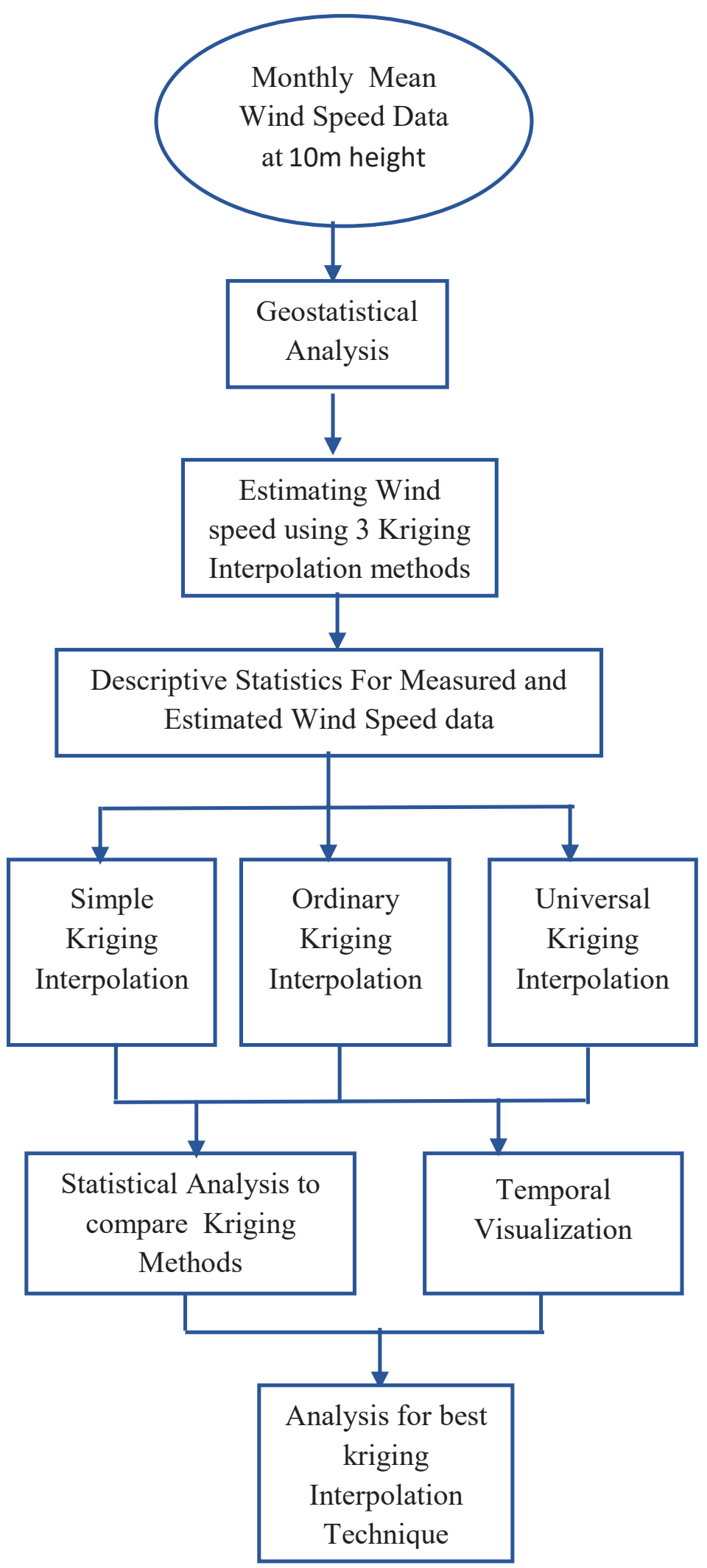

Fig. 2. Schematic diagram to describe the methodology 
estimate the value at a nearby unknown location [20]. Kriging technique estimates unknown values using spatial autocorrelation between sampling points and prediction location. The spatial autocorrelation can be quantified by modeling the data and generating a predicted surface. Varity of kriging techniques has been used for interpolation and mapping purpose. We have utilised three kriging techniques to model the known points to estimate unknown points in the neighborhood and generate prediction maps. These techniques included Simple, Ordinary and Universal Kriging.

\subsubsection{Simple kriging (SK)}

It assumes that the mean of the data is known, which is unlikely happened in most cases.

\subsubsection{Ordinary kriging (OK)}

It is also known as Best Linear Unbiased Estimator (BLUE) for the unknown values. It assumes that the data is stationary and have constant mean.

\subsubsection{Universal kriging (UK)}

This technique is used for non-stationary data i.e. mean of the data is not known in advance.

\section{RESULTS AND DISCUSSION}

\subsection{Geostatistical Analysis}

To carry out this study, in the preliminary stage, Geostatistical analysis was used to estimate measured wind speed using three kriging interpolation techniques: simple kriging, Ordinary kriging, and Universal kriging. In the second stage, descriptive statistics was used to summarise the comparison between measured and estimated wind speed data. Five interpolation methods were reported that have been utilised to estimate wind speed in Iraq and found IDW as best method while Ordinary Kriging stand on second place [21].

\subsection{Descriptive Statistics of Wind Speed Data}

Different statistical measures of wind speed data are presented in (Table 1), which included mean wind speed, minimum and maximum wind speed, median, standard deviation, standard error of mean, skewness and kurtosis. For this station, at a height of 10 meters, the mean estimated wind speed calculated by the Simple kriging method varies from $1.78 \mathrm{~m} / \mathrm{s}$ to $4.13 \mathrm{~m} / \mathrm{s}$ and $1.77 \mathrm{~m} / \mathrm{s}$ to $3.98 \mathrm{~m} / \mathrm{s}$ calculated by the simple kriging method Ordinary and Universal kriging interpolation methods. The mean wind speed and standard deviation values suggested good uniformity in the wind behaviour. The low variance of error values revealed that predicted methods created more precise values. The median values obtained by the estimated methods were 2.767 and 2.776 which were close to its mean value, then the measured data value 2.75 which is far from its mean value. This showed that the estimated wind speed data has a central tendency. The spread of the data from its mean value was measured using standard deviation. Standard deviation value was 0.869 and 0.836 in the kriging estimation method, which was small compared to the standard deviation value of 0.904 for measured wind speed data. This indicated that the measured wind data was more dispersed. The small value of the standard error of the mean was calculated 0.251 in the Simple kriging method and 0.240 in the other two methods, while its value was 0.250 in measured wind speed. The low standard of error of mean in Ordinary kriging and Universal kriging methods showed reliability of the mean. The estimated values were less positively skewed than the measured wind data which showed that estimated wind data was more symmetric about its mean position. The value calculated for kurtosis was -1.46 in Ordinary and Universal kriging methods. It was higher in estimated wind data values, indicating that estimated wind data has very lightly tailed Distribution. The statistical results showed that the kriging technique is more reliable for the estimation and mapping of wind speed data.

\subsection{Statistical Analysis for The Comparison of Kriging Methods}

Different statistical parameters like Pearson's correlation coefficient ' $r$ ', coefficient of determination $\mathrm{R}^{2}$, coefficient of variation $(\mathrm{CV})$, the variance of estimation error were utilised in (Table 2) to see which kriging interpolation method was best to produce prediction values close to observed values. Correlation coefficient ' $r$ ' showed a strong correlation value of 0.999 resulted in 
Ordinary and Universal kriging methods compared to Simple kriging method has this value of 0.991 . The high value of coefficient of determination was 99.8\% obtained in the Ordinary and Universal kriging methods whereas this value calculated for the Simple kriging method was $99.6 \%$. Thus, the Ordinary and Universal kriging methods explained more estimated wind speed variations than the Simple kriging method. The small variance of estimation error value 0.004 has resulted in Ordinary and Universal kriging methods, whereas Simple kriging method showed a high variance of this error which was 0.010 . The small estimation error value showed that Ordinary and Universal kriging methods were least biased than the Simple kriging method. The high correlation coefficient and least biasedness indicated that Ordinary and Universal kriging methods predicted wind speed values close to measured wind speed values than the Simple kriging method and therefore are best interpolator.

\subsection{Graphical Analysis for Error Distribution}

\subsubsection{Histogram Analysis}

Histogram showing the frequency distribution of the estimated wind speed error resulted by three kriging methods and shown in (Figure 3A) and (Figure 3B). The estimation error distribution analysis showed that the Simple kriging method estimated $75 \%$ of the values close to zero, whereas ordinary and Universal kriging methods had estimated $83 \%$ of the values close to zero. The error distribution analysis in histogram showed that Ordinary and Universal kriging methods are the least unbiased than the Simple kriging method. These results show that Ordinary and Universal kriging methods performed better estimation.

\subsubsection{Boxplot Analysis}

Box-plot is also known as the Box-whisker plot, which is a kind of statistical graph that concisely shows the distribution characteristics of data. Boxplot presented in (Figure 4A), (Figure 4B) and (Figure 4C) showing estimation error distribution in terms of quartiles. The error value in Simple kriging method at 3 rd quartile q3 is 0.043 , whereas at 1 st quartile q1, this value is -0.080 . This indicates that $75 \%$ of the error values are equal to or less than 0.043 , whereas $25 \%$ error values are equal to or less than -0.080 . The interquartile range (IQR) value is $\mathrm{q} 3-\mathrm{q} 1=0.123$. This shows that $50 \%$ of the error values are equal to or less than 0.123 . In the case of

Table 1. Descriptive statistics to compare and summarise observed and estimated wind speed data

\begin{tabular}{|c|c|c|c|c|c|}
\hline \multirow{3}{*}{ S.No } & \multirow{3}{*}{ Variable } & \multicolumn{4}{|c|}{ Wind Speed $(\mathrm{m} / \mathrm{s})$} \\
\hline & & \multirow[t]{2}{*}{ Measured } & \multicolumn{3}{|c|}{$\begin{array}{r}\text { Predicted } \\
\end{array}$} \\
\hline & & & Simple Kriging & Ordinary Kriging & Universal Kriging \\
\hline 1) & Minimum & 1.770 & 1.780 & 1.776 & 1.776 \\
\hline 2) & Maximum & 4.270 & 4.135 & 3.983 & 3.983 \\
\hline 3) & Mean & 2.840 & 2.819 & 2.805 & 2.805 \\
\hline 4) & Median & 2.750 & 2.767 & 2.776 & 2.776 \\
\hline 5) & Standard Deviation & 0.904 & 0.869 & 0.836 & 0.836 \\
\hline 6) & Standard Error of Mean & 0.261 & 0.251 & 0.242 & 0.242 \\
\hline 7) & Skewness & 0.310 & 0.220 & 0.150 & 0.150 \\
\hline 8) & Kurtosis & -1.280 & -1.420 & -1.460 & -1.460 \\
\hline
\end{tabular}

Table 2. Statistical analysis for the comparison of kriging methods

\begin{tabular}{lccccc}
\hline S.No & $\begin{array}{c}\text { Statistics } \\
\text { For Kriging } \\
\text { Methods }\end{array}$ & $\begin{array}{c}\text { (r) between } \\
\text { Measured and Predicted } \\
\text { Wind Speed Values }\end{array}$ & $\mathbf{R}^{\mathbf{2}} \mathbf{( \% )}$ & $\mathbf{C V}(\mathbf{\%})$ & $\begin{array}{c}\text { Variance of } \\
\text { Estimation Error }\end{array}$ \\
\hline 1) & Simple & 0.991 & 99.6 & 30.38 & 0.010 \\
2) & Ordinary & 0.999 & 99.8 & 30.73 & 0.004 \\
$3)$ & Universal & 0.999 & 99.8 & 30.73 & 0.004 \\
\hline
\end{tabular}

r-Coefficient of Correlation, $\mathbf{R}^{2}$-Coefficient of Determination, CV-Coefficient of Variation 
Ordinary and Universal kriging method, the error value at the 3 rd quartile $\mathrm{q} 3$ is 0.0119 , whereas at 1 st quartile q1 the value is -0.024 . This shows that $75 \%$ error values are equal to or less than 0.0119 , whereas $25 \%$ values are equal to or less than -0.024 . The mean error value -0.02 showed in dashed lines in Ordinary and Universal kriging methods is close to zero, whereas this mean error value is -0.035 in case of Simple kriging method, and it is slightly far from zero value. The IQR was 0.036 , which means that $50 \%$ of the error values are equal to or less than this IQR value. The quartile and interquartile range values showed that more percentage of the error values are close to zero in the Ordinary and Universal kriging method compared to the Simple kriging method. The box plot analysis confirms that the Ordinary and Universal kriging methods estimated wind speed values close to measured values.

\subsubsection{Individual Value Plot Analysis}

The individual value plot was used here to show the distribution of individual error values. In (Figure 5A), the plot clearly shows that in the case of Simple kriging method, the error values are not close to zero value. The mean value of error is -0.035 in the Simple kriging method, which is also not close to zero. Whereas in Ordinary and Universal kriging methods, the mean error value is -0.02 , which is close the zero. All other error values are also close to zero as shown in (Figure 5B). From the graphical representation of the distribution of error value, it is also very clear that Ordinary and Universal kriging methods are better interpolation

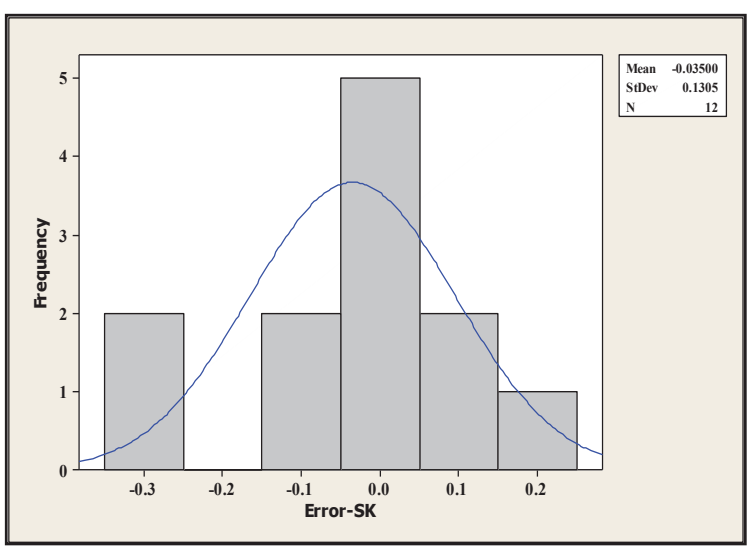

3A estimators than the Simple kriging method.

\subsubsection{Time Series Plot}

The quantitative change of one year means wind speed data is presented in a time series plot in (Figure 6). The plot shows seasonal variations and increasing trends. The time series plot shows minimum wind speed in the winter and high in the summer. Figure shows the minimum and maximum wind speed lies around $2.0 \mathrm{~m} / \mathrm{s}$ to $2.5 \mathrm{~m} / \mathrm{s}$ in the winter season between December and February. The summer season showing increasing trend starting from the month of March till September. These months showing moderate to high wind speed variations. The wind speed maximum values are almost $3.0 \mathrm{~m} / \mathrm{s}$ to $4.3 \mathrm{~m} / \mathrm{s}$. Results indicate that summer seasons comprise $75 \%$ of moderate to high wind speed class and $25 \%$ have moderate wind speed class in the winter season. Moderate to high wind speed variations in both seasons are suitable for small scale wind power generation. They are showing detailed wind speed distribution both for the summer and winter months.

\subsection{Temporal Mapping}

The Temporal maps were generated using Simple, Ordinary and Universal Kriging methods for the twelve months mean monthly wind speed data shown in (Figure 7A), (Figure 7B) and (Figure 7C). The annual wind speed pattern obtained by Ordinary and Universal kriging interpolation methods than SK method. Further, the summer months show similar and more detailed variations in OK and UK

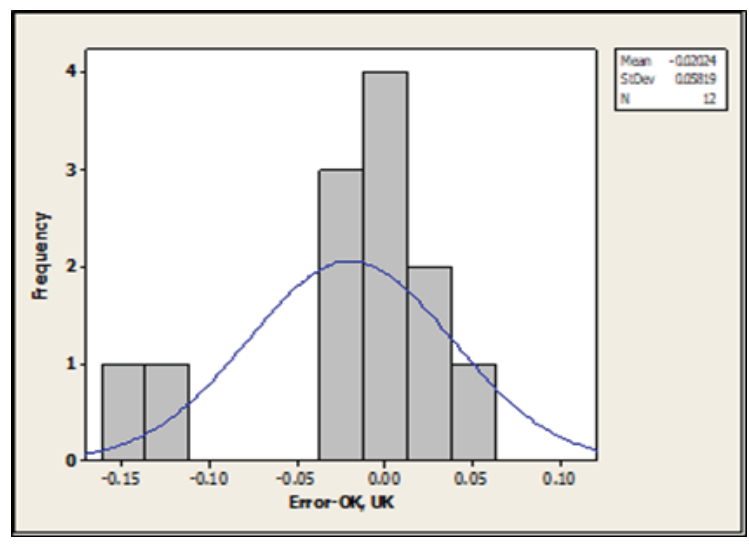

3B

Fig. 3(A-B). Histogram of estimation error for 3A) SK and 3B) OK and UK method Simple Kriging (SK), Ordinary Kriging (OK) and Universal Kriging (UK) 
methods than in the winter months. Less variations in winter season were observed in DecemberFebruary months (visible in blue and grey shades) in (Figure 7A), in SK methods than the other two methods whereas more variations were observed in summer months from March-September visible in light yellow to red colors) in (Figure 7B \&7C).

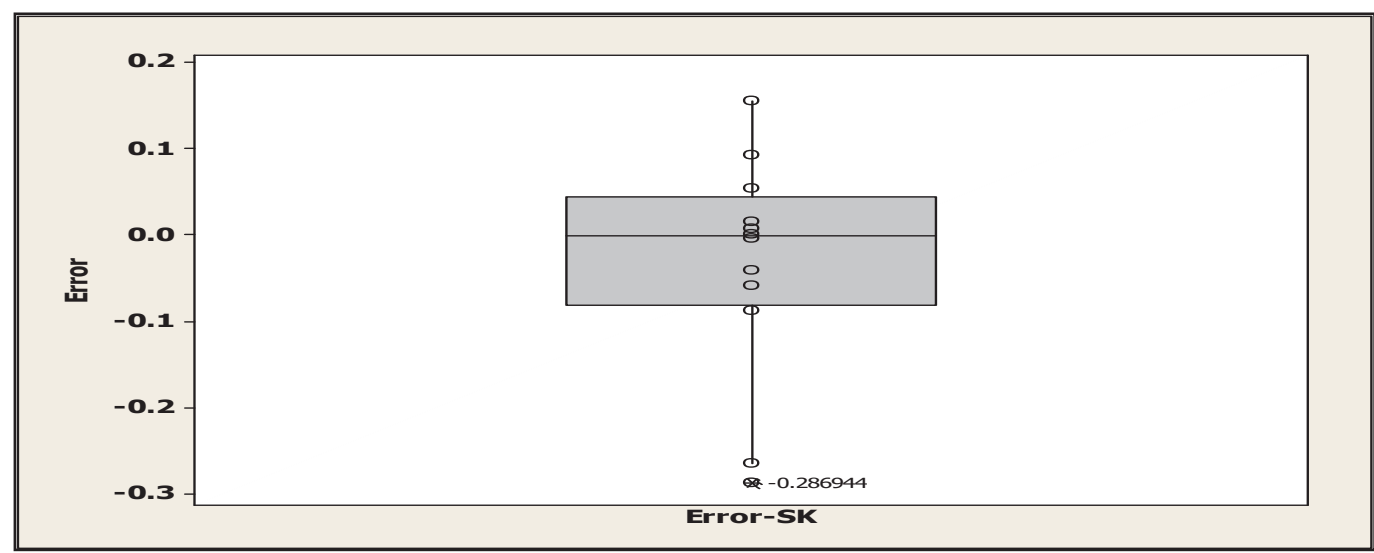

4A

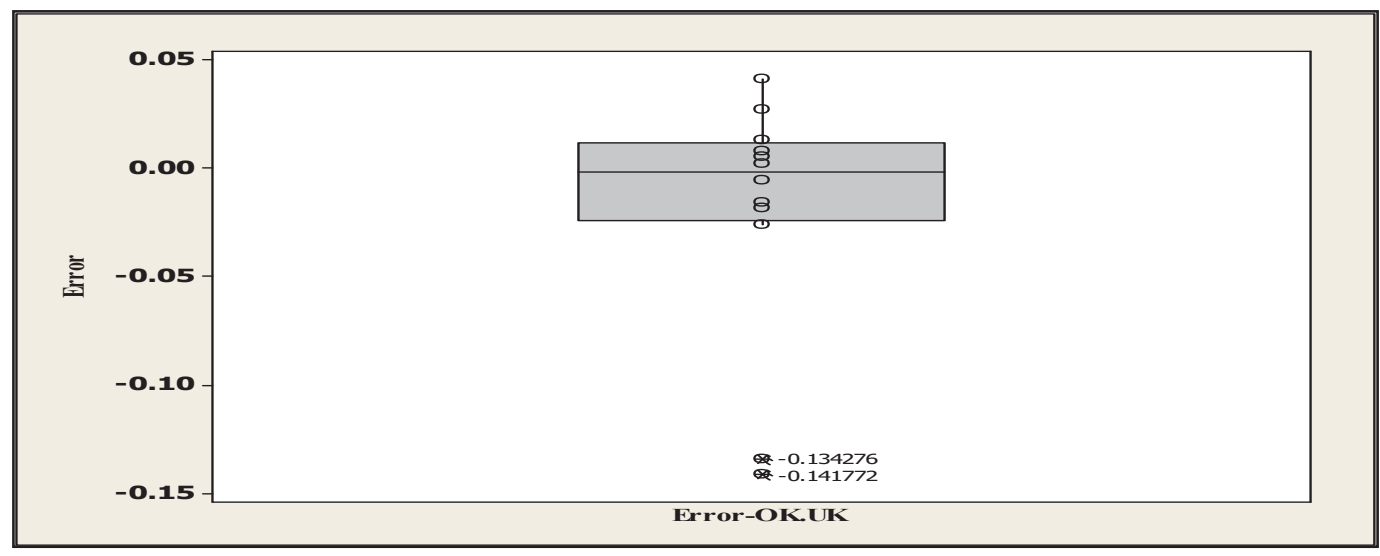

4B

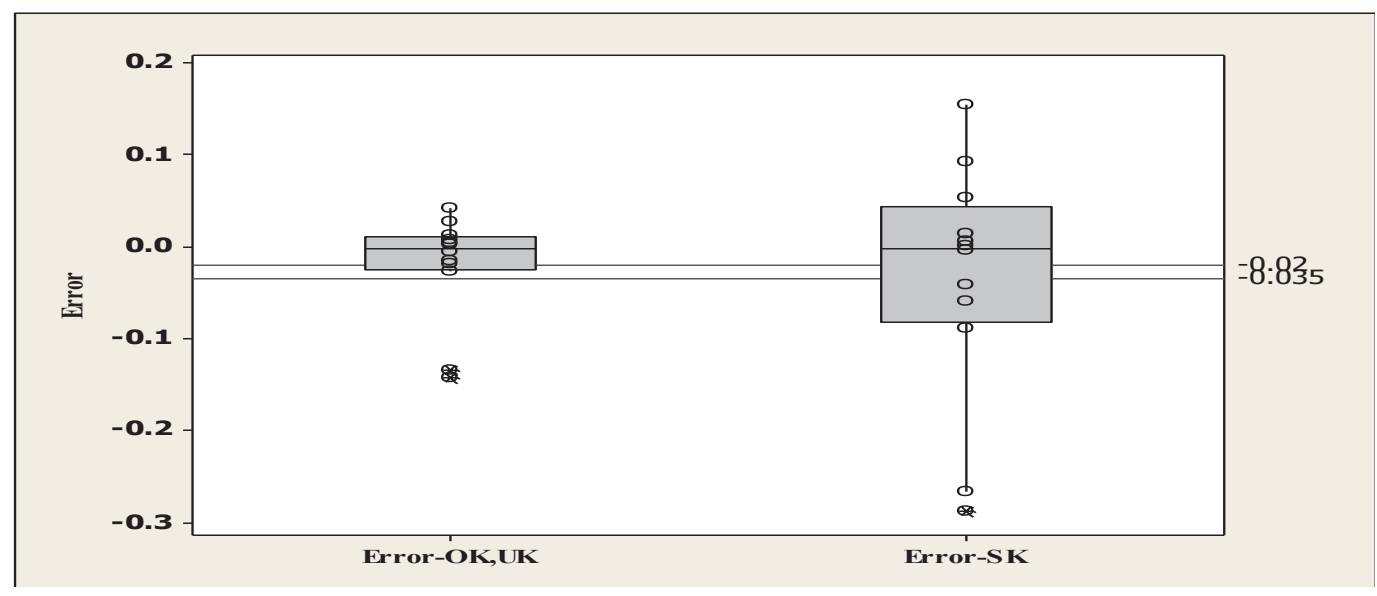

$4 \mathrm{C}$

Fig. 4(A-C). Boxplot of estimation error of 4A) Simple, 4B) Ordinary and Universal Kriging methods, and 4C) Combined effect of three methods 


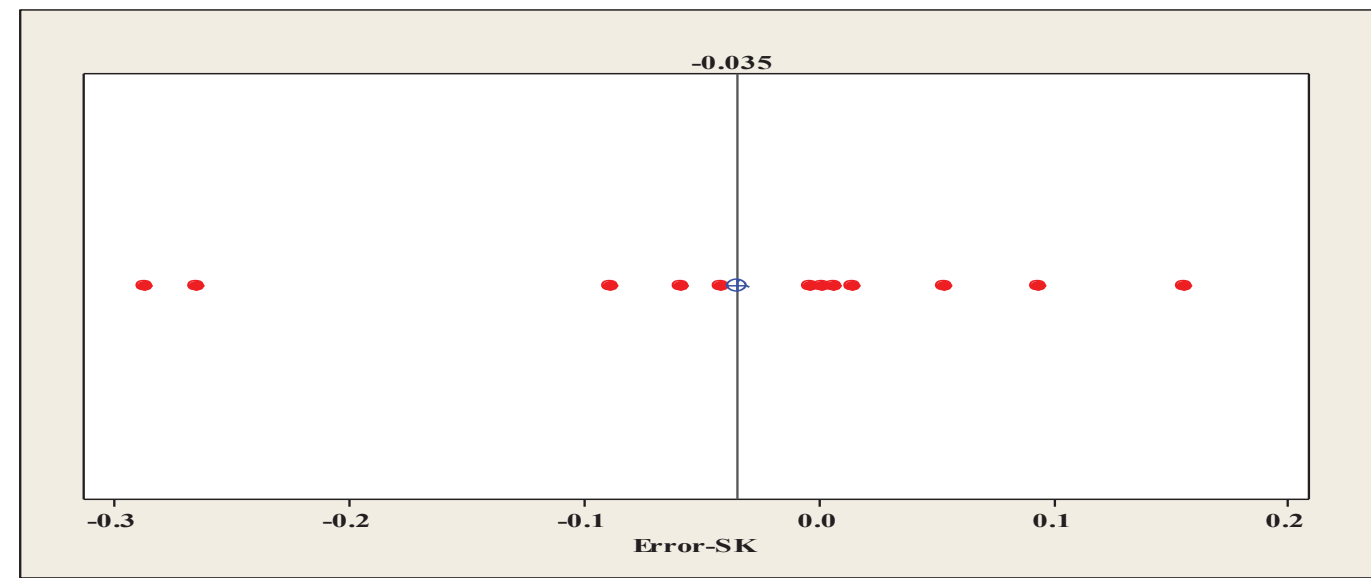

5A

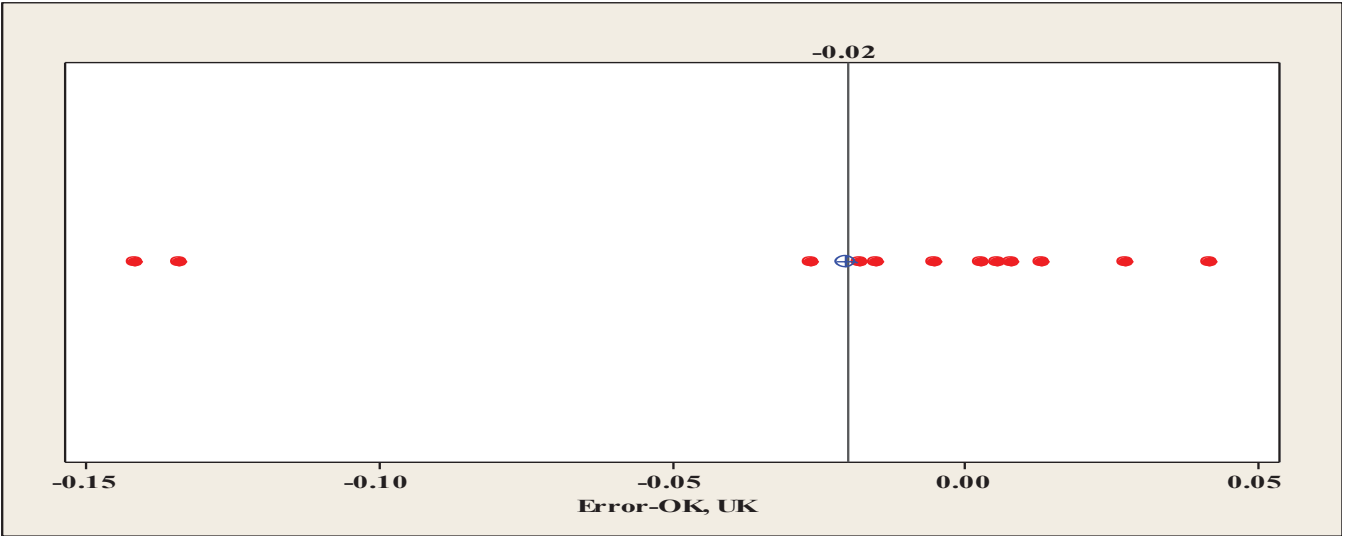

5B

Fig. 5(A-B). Individual value plot of estimation error of 5A) Simple, 5B) Ordinary and Universal kriging methods

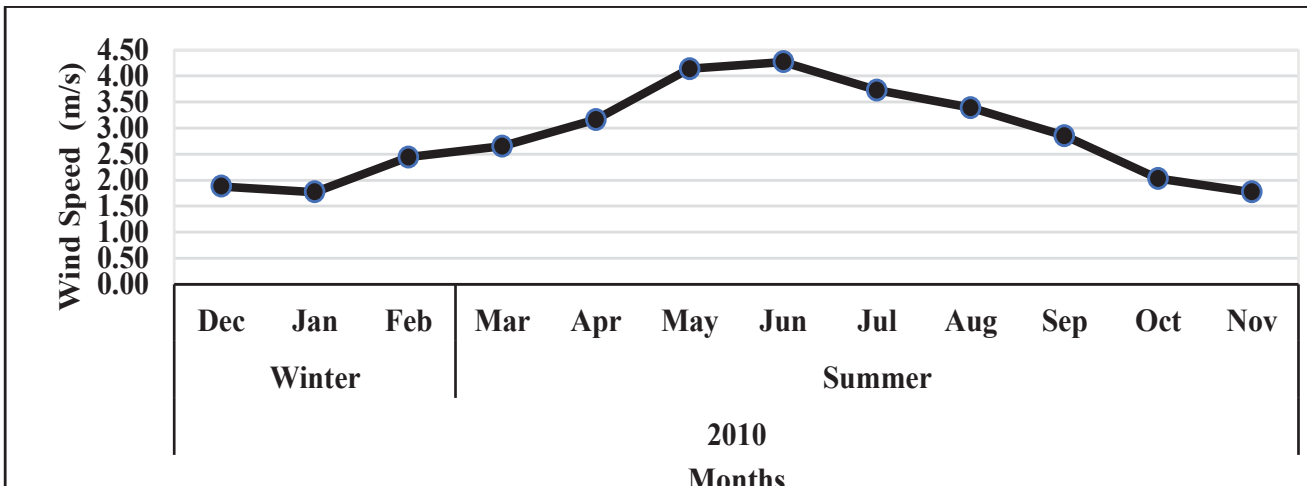

Fig. 6. Time series plot of monthly wind speed (m/s) for 2010 at Karachi Airport 


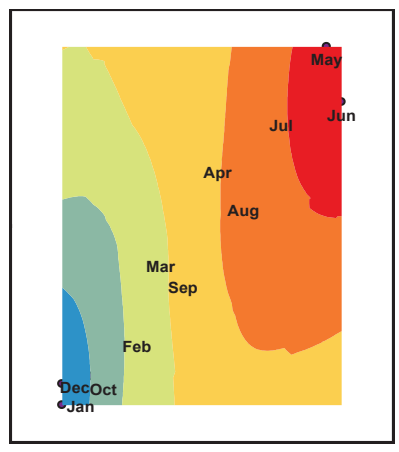

7A

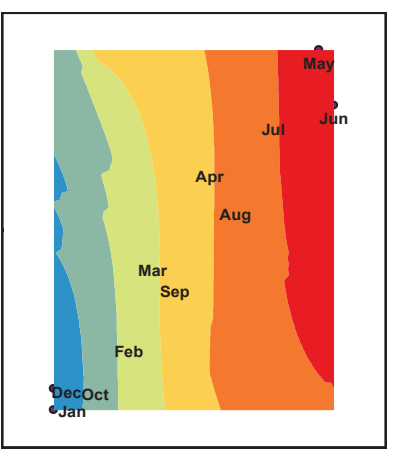

$7 \mathrm{~B}$

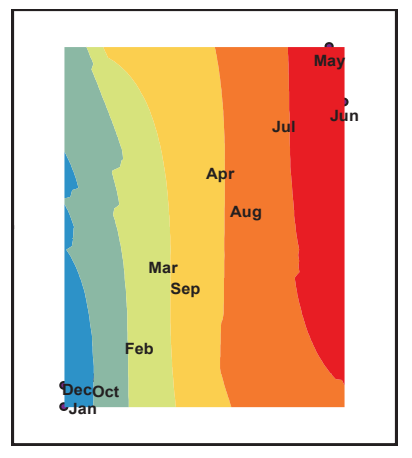

Legend

Prediction Map

of Wind Speed (m/s)

at K.A

Values

$1.77-2.02$

2.02-2.33

2.33-2.72

$2.72-3.20$

$3.20-3.79$

$3.79-4.27$

7C

Fig. 7(A-C). Temporal maps of monthly mean wind speed for 2010 at Karachi Airport (K.A.) using 7A) Simple, 7B) Ordinary and 7C) Universal Kriging methods

\section{CONCLUSIONS}

The following conclusions were drawn from the results obtained in this study:

a ) In this analysis work, wind speed estimation at unmeasured locations of the study area was performed using three Kriging interpolation techniques of GeoStatistics. The descriptive statistical analysis of the estimated wind speed showed that the estimation methods gave more prices results as they accurately measured wind speed close to actual wind speed. The analysis also indicated that Ordinary and Universal Kriging methods had better estimation results than the Simple Kriging technique.

b) The estimation technique is useful as it saves wind measuring tower installing costs at unsampled and remote locations. As described earlier, constructing a wind system such as a wind measurement or wind harvesting machine is very costly [22]. Studies on wind characteristics of the site before constructing a wind system are needed to reduce costs. The wind characteristic is one of the significant studies to determine the suitable sites for wind system construction. As stated earlier, a GIS-based spatial wind mapping provides a geographical distribution of wind resources and is very useful for decision-making and planning in wind energy development [23].

c ) The Ordinary and Universal Kriging techniques were found more accurate than SK technique because of A) the two methods provided strong autocorrelation between actual and estimated wind data points. B) These methods showed less unbiasedness between the two wind speeds data points than the Simple kriging method and C) The strong autocorrelation produced low estimation errors and finally generated a smooth continuous surface.

d) The high correlation value in $\mathrm{OK}$ and UK methods shows a positive association between surrounding values and an increasing trend from winter to summer months. Spatial autocorrelation is a fundamental concept in spatial analysis. Positive spatial autocorrelation means that geographically nearby values of a variable tend to be similar on a map [24]. The strong correlation indicates that estimating wind speed at unsampled locations is similar to referenced wind data points. The high correlation is also reflected in the maps produced by these two methods.

e ) More detailed maps were produced by the two method, which was another feature due to the high correlation. The details were more enhanced in seven summer months than the winter months. Its mean that these months are suitable to generate wind power.

f) The low variance of error also supports the estimation method as it gives an idea to select a suitable place for wind power generation.

g) It is concluded that the analysis done in this article seems an initial assessment to see the effectiveness of the Geostatistical estimation method using kriging interpolation technique. The wind speed at the study area is the point distribution on the map. The kriging interpolation technique is useful for determining the destitution of wind speed at potential sites. Beside saving tower installation cost, this technique also saves long time period in just selecting a place suitable for wind power 
generation. The estimation technique will very much effective in two ways. A) to install wind turbine at a suitable place outside the urban area and connect it with a power grid network. This will help provide power to urban areas that are more affected by the power loadshaing problem. B) installing wind turbines within community areas to produce small scale wind power.

h) The Geostatistical kriging methods may give better estimation results if more detailed wind speed data at different heights are available. It will also help to install wind turbines at higher heights to generate more wind power.

\section{ACKNOWLEDGEMENT}

We are grateful to Pakistan Metrological Department for providing the wind speed data for this research.

\section{CONFLICT OF INTEREST}

The authors declare no conflict of interest.

\section{REFERENCES}

1. B. Yaniktepe, T. Koroglu, and M. Savrun. Investigation of wind characteristics and wind energy potential in Osmaniye, Turkey. Renewable and Sustainable Energy Reviews 21: 703-711 (2013).

2. J. Wu, J. Wang, and D. Chi. Wind energy potential assessment for the site of Inner Mongolia in China. Renewable and Sustainable Energy Reviews 21: 215-228 (2013).

3. H. Chai, W. Cheng, C. Zhou, X. Chen, X. Ma, and S. Zhao. Analysis and comparison of spatial interpolation methods for temperature data in Xinjiang Uygur Autonomous Region, China. Natural Science 3(12): 999 (2011).

4. F. Collins, and P. Bolstad. A comparison of spatial interpolation techniques in temperature estimation. In proceedings of the Third International Conference. Paper presented at the Workshop on Integrating GIS and Environmental Modeling, Santa Fe, New Mexico (1996).

5. P. Goovaerts. Performance comparison of geostatistical algorithms for incorporating elevation into the mapping of precipitation. Paper presented at the The IV International Conference on GeoComputation was hosted by Mary Washington
College in Fredericksburg, VA, USA (1999).

6. D.L. Phillips., J. Dolph, and D. Marks. A comparison of geostatistical procedures for spatial analysis of precipitation in mountainous terrain. Agricultural and forest meteorology 58(1-2): 119-141 (1992).

7. S.M. Serrano, M.A. Sánchez, and J. M. Cuadrat. Comparative analysis of interpolation methods in the middle Ebro Valley (Spain): application to annual precipitation and temperature. Climate research 24(2): 161-180 (2003).

8. Q. H. Escobedo, R. S. Flores, E. R. García, and F. M. Agugliaro. Wind energy resource in Northern Mexico. Renewable and Sustainable Energy Reviews 32: 890-914 (2014).

9. Y. V. Yap. Estimation and Validation of Wind Speed by using Spatial Interpolation. Thesis B.Eng. (Hons.) Civil Engineering, University of Malaysia Pahang, Mayalsia (2015).

10. W. Luo, M. Taylor, and S. Parker. A comparison of spatial interpolation methods to estimate continuous wind speed surfaces using irregularly distributed data from England and Wales. International Journal of Climatology: A Journal of the Royal Meteorological Society 28(7): p. 947-959 (2008).

11. B. Cabrera. A geostatistical method for the analysis and prediction of air quality time series: application to the Aburrá Valley region. Master Thesis. Technical University of Munich, Germany (2016).

12. M.A. Ahmed, F. Ahmed, and M.W. Akhtar. Assessment of wind power potential for coastal areas of Pakistan. Turkish Journal of Physics 30(2): 127-135 (2006).

13. Q.Z. Chaudhry. An investigation on wind power potential of Gharo-Sindh, Pakistan. Pakistan journal of meteorology 6(11): (2009).

14. M.A. Chaudhry, R. Raza, and S.A. Hayat. Renewable energy technologies in Pakistan: prospects and challenges. Renewable and Sustainable Energy Reviews 13(6-7): 1657-1662 (2009).

15. M.A. Hussain, S. Abbas, M.R. Ansari, A. Zaffar, and B. Jan. Wind speed analysis of some coastal areas near Karachi. Pakistan Academy of Sciences (2012).

16. M.H. Baloch, G.S. Kaloi, and Z.A. Memon. Current scenario of the wind energy in Pakistan challenges and future perspectives: A case study. Energy Reports 2: 201-210 (2016).

17. Z.H. Hulio, W. Jiang, and S. Rehman. Technical and economic assessment of wind power potential of Nooriabad, Pakistan. Energy, sustainability and Society 7(1): 1-14 (2017). 
18. M. Ahmed, M. N. Ali, and I. A. Memon. A review of wind energy potential in Sindh, Pakistan. Paper presented at the AIP Conference Proceedings (2019).

19. S. Reman, M. U. Qazi, I. Siddiqui, and N. Shah. Comparing Geostatistical and Non-geostatistical Techniques for the Estimation of Wind Potential in Un-sampled Area of Sindh, Pakistan. European Academic Research 1770-1792 (2013).

20. P. Gipe. Wind power, Wind Engineering, James \& James/Earthscan, London 28(5): 629-631 (2004).

21. S. Ali, A. Mahdi, and A. H. Shaban. Wind speed estimation for Iraq using several spatial interpolation methods. environmental protection, 1: 2 (2012).

22. D.G. Krige. Two-dimensional weighted moving average trend surfaces for ore-evaluation. Journal of the South African Institute of Mining and Metallurgy 66: 13-38 (1966).

23. E. Sreevalsan. Indian Wind Atlas: Centre for Wind Energy Technology (2010).

24. A. Getis. A history of the concept of spatial autocorrelation: A geographer's perspective. Geographical analysis 40(3): 297-309 (2008). 